\title{
Mejoramientos de envolvente para la eficiencia energética de viviendas en el centro-sur de Chile
}

\section{Envelope improvements for energy efficiency of homes in the south-central Chile}

O. Escorcia ${ }^{(*)}$, R. García(**), M. Trebilcock ${ }^{(* *)}$, F. Celis ${ }^{(* * *)}$, U. Bruscato ${ }^{(* * * *}$

\section{RESUMEN}

Este manuscrito forma parte del proyecto "Diseño Integrado para la Reconstrucción de Viviendas Energéticamente Eficientes". Presenta evaluación y diagnóstico de condiciones constructivas y energéticas de viviendas de las tres regiones más afectadas en el centro-sur de Chile por el terremoto del 27 febrero de 2010. A ese propósito revisa e identifica, en el marco de la normativa actual, las condiciones generales y características de las envolventes predominantes en viviendas de 22 ciudades; analiza su comportamiento energético y recomienda medidas de acondicionamiento térmico de viviendas en ejecución o en uso, decisivas para el ahorro y la eficiencia energética. Formula una estrategia de mejoramiento energético residencial en las envolventes verticales con una base y dos escenarios de análisis comparativos. Propone una planeación económica, constructiva y arquitectónicamente efectiva, con posibilidades de implementación social y financiera, que podría colaborar sustancialmente a la eficiencia energética.

$113-120$

Palabras clave: Eficiencia energética; ahorro energía; vivienda envolvente; soluciones constructivas; Chile.

\section{SUMMARY}

This manuscript is part of the research project "Integrated Design for Energy Efficient Housing Reconstruction." It exposes the diagnosis of energy and construction conditions of dwellings of 3 regions in the south central area of Chile, which was the most affected by the earthquake of February 27th, 2010. With this aim, it reviews predominant characteristics of the building envelopes in 22 cities. It analyzes energy performance and it recommends thermal improvements for dwellings either under construction stage or during occupancy stage, which are critical for energy savings and efficiency. It proposes strategies to improve energy efficiency through vertical envelopes, with a base case and two comparative scenarios. It proposes economic, constructive and architectural planning strategies, with the possibilities of social and financial implementation, which could help substantially to achieve energy efficiency.

Keywords: Energy efficiency; energy savings; enveloping home; building solutions; Chile.

\footnotetext{
(*) Universidad Nacional de Colombia, Bogotá (Colombia).

(*) Universidad del Bío-Bío, (Chile).

(***) Universidad de Alcalá de Henares, Madrid (España)

(****) Universidade Federal do Rio Grande do Sul, (Brasil).

Persona de contacto/Corresponding author: oescorciao@unal.edu.co (O. Escorcia)
}

Recibido/Received: 16 dec 2011 Aceptado/Accepted: 14 feb 2012 Publicado online/ Published online: 03 oct 2012 


\section{INTRODUCCIÓN}

El terremoto del 27 de febrero de 2010 -27F- que afectó la zona centro-sur, modificó sustancialmente la manera como venía resolviéndose el déficit habitacional en Chile y el reacondicionamiento térmico de viviendas. De una evolución proyectada desde 2006 a un ritmo del 2,5\% anual acumulado, que en términos absolutos implicó pasar de 1.007.253 viviendas en 2006 a 805.796 viviendas a finales de 2009, las cifras del déficit aumentaron para 2010 a 1.175.838 viviendas, es decir un incremento respecto al año inmediatamente anterior del $45,9 \%$, lo cual significó un retroceso de más de cinco años (1). Por otra parte, la amplia participación de la vivienda en el consumo energético nacional, $22 \%$, según la Comisión Nacional de Energía de Chile (CNE) (2) subraya la preocupación por avanzar de manera sostenida y significativa en el tema de la eficiencia energética (EE).

En ese escenario, la envolvente térmica de la vivienda encabeza la lista de requerimientos para limitar la demanda energética y es también factor fundamental de EE. Chile enfrenta el reto energético mediante dos estrategias paralelas, la primera, aumentando la capacidad instalada del país y la segunda, reduciendo la creciente demanda energética. En esta última, ha expresado esa necesidad desde hace algunos años mediante la implementación primero de un programa de Reglamentación enfocado al Acondicionamiento Térmico de Viviendas (3), estrategia que regula con la entrada en vigencia desde el año 2000 de la Reglamentación Térmica (RT), mandato-ley en la Ordenanza General de Urbanismo y construcciones (Art. 4.1.10. OGUC) que divide el país en 7 zonas térmicas. Programada en tres etapas, la primera regula las techumbres en el año 2000; la segunda a muros, ventanas y pisos ventilados en el 2007, que pretende culminar próximamente en una tercera etapa, con la puesta en vigencia de la certificación energética, en la idea de abarcar todas las variables que afectan los rendimientos energéticos (ubicación geográfica, materialidad) y una serie de aspectos combinados que mejoran la calidad de las viviendas en distintas zonas del país, apoyados con el uso de herramientas informáticas de simulación, que se suman a las cuatro alternativas existentes para cumplir con los requerimientos de la $\mathrm{RT}^{1}$.

La RT marca el punto de partida para las definiciones de parámetros de calidad térmica de viviendas y establece exigencias mínimas para las envolventes residenciales, ligados al concepto de grados-día de calefacción anuales (GDCA) determinantes de valores de transmitancia y resistencia térmica. Los GDCA se definen a partir de una temperatura base interior de $15^{\circ} \mathrm{C}$, y para lograr el estándar recomendable de confort de 18 a $20{ }^{\circ} \mathrm{C}$ se equilibra con las ganancias internas propias de un régimen de operación pleno de la vivienda, estimación que no resulta necesariamente recomendable por estudios realizados (4) pues sus estándares no constituyen hoy una garantía de eficiencia energética, especialmente en vivienda social, siendo requerimiento básico empezar a observar otros enfoques que contemplen las condiciones locales de clima.

Actualmente se reconocen esfuerzos en el campo práctico, tanto de los sectores públicos como privados y algunos estudios lo analizan desde enfoques cualitativos (5) sugiriendo medidas para adelantar acciones más efectivas. El sector público, por un lado, más preocupado por la EE mediante el acondicionamiento térmico de viviendas, fomenta a través de subsidios dirigidos a mejorar fundamentalmente la envolvente térmica, en la idea de alcanzar ahorros en calefacción y mejoramiento del confort higrotérmico de viviendas, así también, con subsidios tributarios enfocados a motivar la incorporación de energías renovables no convencionales a las viviendas nuevas y existentes.

Por su parte los esfuerzos privados, en línea con las agendas ambientales de los países en desarrollo y más inclinados a objetivos locales dedicados más a mejorar las condiciones de habitabilidad y confort de las viviendas que a objetivos ambientales globales de contaminación, son una apuesta comercial interesante que compromete a profesionales y a usuarios, en un ejercicio de doble beneficio que permitiría en una acción de largo aliento, a los profesionales presentar proyectos eficientemente energéticos y a usuarios, un ahorro en los consumos energéticos por calefacción.

Ese es el punto de partida y contexto del Proyecto MEL 81100003 CONYCIT "Diseño Integrado para la Reconstrucción de Viviendas Energéticamente Eficientes" (DIRVEe) 2011-2012, y referencia para la revisión que este trabajo hace de las envolventes de viviendas, en tres de las regiones más afectadas por el terremoto del 27F, con el propósito de establecer estrategias de acondicionamiento energético de viviendas existentes y para la reconstrucción de viviendas con criterio de EE.

La metodología utilizada compagina técnicas descriptivas con otras de tipo experimental y analíticas que articulan su desarrollo en tres fases. La primera de carácter 
exploratoria y descriptiva, apoyada en la normativa vigente, estadísticas nacionales, registro fotográfico y fichas técnicas, realiza un observatorio por ciudades representativas para identificar tipologías de viviendas, condiciones constructivas y características de envolventes predominantes. La segunda, descriptiva, mediante entrevistas a profesionales, funcionarios y usuarios, determina condicionantes en la normativa, en etapas de diseño, de construcción y operación de la vivienda, que afectan el comportamiento de envolventes y los ahorros energéticos que pudieran lograrse.

La tercera, experimental, a través de software de simulación (Ecotect) maneja valores límites de la RT (techumbres, fachadas y ventanas) y otros indicadores de desempeño, no contemplados (puentes térmicos y ventanas); para el análisis de las envolventes predominantes, selecciona 8 muestras de las 22 ciudades observadas, fija caso base y predice la posibilidad de medir y calificar el desempeño energético de dos escenarios-propuestas de mejoramiento.

Esta fase se complementa con un trabajo analítico, también predictivo, de evaluación del consumo de energía para calefacción aplicando la metodología clásica a partir de la ecuación de consumo anual que contiene: los grados-días anuales de la zona climática respectiva y las características de la vivienda, esto es su transmitancia volumétrica $\mathrm{G}$ y el volumen de la vivienda V. Las estrategias de amortización planteadas para la recuperación de la inversión se calculan empleando técnicas de análisis financieros (VAN-TIR), proponiendo varias alternativas de retorno.

\section{CARACTERÍSTICAS DE LA ENVOLVENTE}

La envolvente es el mecanismo de un edificio para asegurar la habitabilidad y confort a su interior. Energéticamente es factor decisivo de eficiencia energética. La amplia participación de la vivienda en el consumo energético marca la preocupación en este tema que definen para Chile acciones de reacondicionamiento térmico y otras para la reconstrucción de las regiones afectadas por el $27 \mathrm{~F}$. A esa fecha, el $74 \%$ de viviendas construidas antes del 2000 no cumplían con la RT y sólo el $19 \%$ estarían acogidas a la aislación de techumbre (6), adicionalmente la techumbre es el único elemento de la envolvente adecuado a los climas y con capacidad para limitar la demanda, salvo para muros en zona $7\left(0,6 \mathrm{~W} / \mathrm{m}^{2} \mathrm{~K}\right)$ con una menor transmitancia térmica que en el resto de las zonas térmicas en que se divide el país (Tabla 1), la cual deberá disminuir con la elevación de estándares de confort.

Tabla 1. Tabla de la RT (Art. 4.1.10. OGUC), 7 zonas térmicas definidas con base al criterio de GDCA y valores límites de transmitancia y resistencia térmica para los componentes de la envolvente.

\begin{tabular}{|c|c|c|c|c|c|c|}
\hline ZONA & \multicolumn{2}{|c|}{ TECHUMBRE } & \multicolumn{2}{|c|}{ MUROS } & \multicolumn{2}{|c|}{ PISOS VENTILADOS } \\
\hline & $\underset{W / \mathrm{m}^{2} \mathrm{~K}}{\mathrm{U}}$ & $\begin{array}{c}\mathrm{Rt} \\
\mathrm{M}^{2} \mathrm{~K} / \mathrm{W}\end{array}$ & $\underset{W / m^{2} K}{U}$ & $\begin{array}{c}\mathrm{Rt} \\
\mathrm{M}^{2} \mathrm{~K} / \mathrm{W}\end{array}$ & $\underset{W / m^{2} K}{U}$ & $\begin{array}{c}\mathrm{Rt} \\
\mathrm{M}^{2} \mathrm{~K} / \mathrm{W}\end{array}$ \\
\hline 1 & 0,84 & 1,19 & 4,0 & 0,25 & 3,60 & 0,28 \\
\hline 2 & 0,60 & 1,67 & 3,0 & 0,33 & 0,87 & 1,15 \\
\hline 3 & 0,47 & 2,13 & 1,9 & 0,53 & 0,70 & 1,43 \\
\hline 4 & 0,38 & 2,63 & 1,7 & 0,59 & 0,60 & 1,67 \\
\hline 5 & 0,33 & 3,03 & 1,6 & 0,63 & 0,50 & 2,00 \\
\hline 6 & 0,28 & 3,57 & 1,1 & 0,91 & 0,39 & 2,56 \\
\hline 7 & 0,25 & 4,00 & 0,6 & 1,67 & 0,32 & 3,13 \\
\hline
\end{tabular}

Otra referencia normativa en Chile, que no tiene carácter obligatorio, es la norma NCh 1079. Of.2008, la cual subdivide el país en una más amplia zonificación climático-habitacional: 9 frente a las 7 zonas térmicas de la $\mathrm{RT}^{2}$.

Se efectuaron visitas a terreno, analizando los sistemas constructivos más utilizados en la envolvente de viviendas, con un registro fotográfico. El estudio se concentra en las Regiones del Maule (VII), del Bío-Bío (VIII) y de la Araucanía IX), ubicadas en el centro-sur de Chile. Su población sumada, corresponde al $24 \%$ del total del país (7) (Figura 1). La Región del Maule tiene una superficie de 30.396,10 hectáreas, 6\% de la superficie del país y 908.097 habitantes, equivalente al $6 \%$ de la población nacional, su capital es Talca. La Región del Bio-Bío con una superficie de 3.706.870 hectáreas, $4,9 \%$ de la superficie del país, es la segunda en población con 1.861.562 habitantes y un $12,3 \%$ de la población nacional, su capital Concepción, fue una de las más afectadas por el terremoto del 27F. La Araucanía con superficie de 3.184.230 hectáreas, representando el $4,2 \%$ de la superficie del país, tiene una población de 869.535 habitantes, equivalente al 5,8\% de la población nacional, su capital Temuco. La población es eminentemente de carácter urbano y se distribuye en las principales ciudades (8) (Figura 2).

${ }^{2}$ La sub-zonificación es estrategia de la regulación térmica internacional para el control de la eficiencia energética. Ver Código Técnico de Edificación español -12 zonas- y otras internacionales. En Chile, proyecto Fondecyt 0617-88 propone siete -7- zonas climáticas y 24 sub-zonas climáticohabitacionales, lo cual permitiría particularizar los consumos.

http://cdocs.minvu.cl/ficha.asp?xld=11

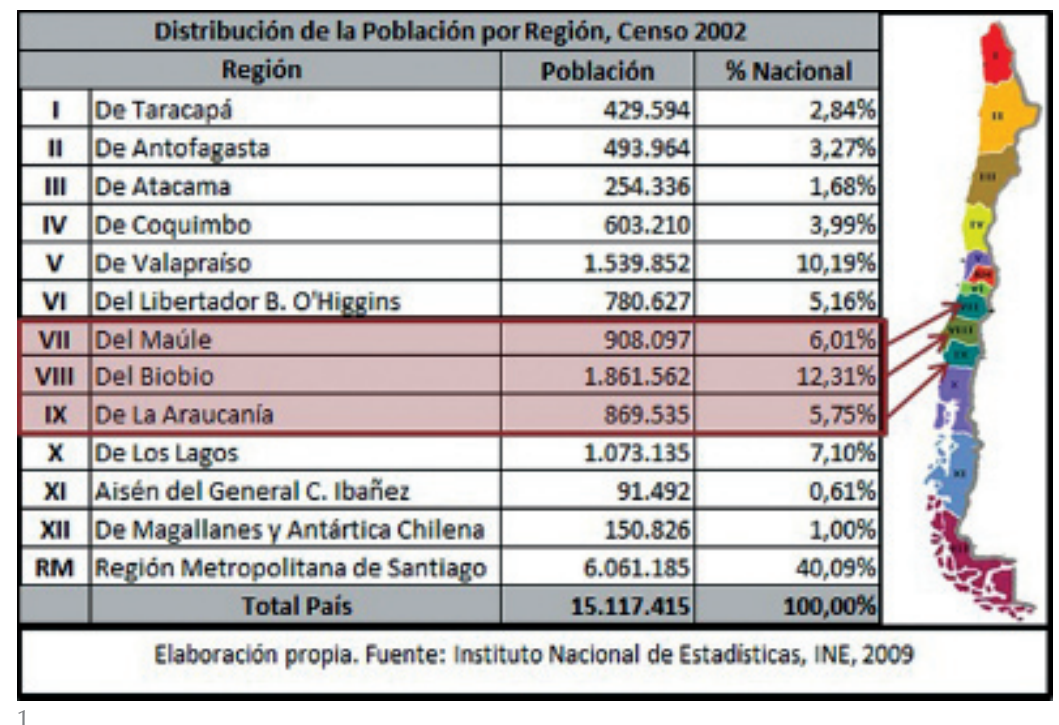


2. Población eminentemente urbana en las tres regiones de estudio, siguen la tendencia nacional. Fuente (INE 2009)

. Tipología arquitectónica en 22 ciudades de estudio. Destaca la vivienda unifamiliar y la mayor concentración en la región VIII del Bio-Bio.

4. Representa población según zonas Térmicas (ZT) y climáticas (ZCL) de ciudades en regiones de estudio. La mayor concentración se presenta en la ZT-4 donde se simplifican 4 de las ZCL: CL-4Cl-5-, SL-6- y SI-7-.

${ }^{3}$ Las viviendas urbanas han aumentado en $34,2 \%$ y las rurales lo han hecho en $13 \%$. Ver Síntesis de resultados Censal 2002 en http://www.ine. cl/canales/menu/indice_tematico.php

${ }^{4}$ Ver. Estrategia 3. Vivienda en Plan de Reconstrucción Sustentable, Constitución PRES, pág. 99 patrocinado por la Universidad de Talca, Arup, Elemental, Fundación Chile y Arauco. www.presconstitución.cl
La composición del parque habitacional corresponde con hogares y vivienda (24\%) del total del país y mantiene la distribución estadística (INE 2000) en un predominio de vivienda urbana sobre rural ${ }^{3}$ donde destacan los tipos unifamiliares en uno y dos pisos sobre multifamiliares en altura (Figura 3), salvo contadas excepciones como puede ser el caso de la población de Constitución, donde el Plan de Reconstrucción Sustentable (PRES) prioriza la densificación ${ }^{4}$, acción especifica adelantada por el gobierno local para mitigar los efectos del $27 \mathrm{~F}$.

Para la revisión de las condiciones constructivas de envolvente de estas regiones se selecciona una muestra de 22 ciudades representativas por mayor población, que pertenecen a 3 zonas térmicas -4, 5 y 6 -, de la RT y corresponden igualmente, a 5 zonas climáticas -4, 5, 6, 7 y 9-de la NCh 10792008. Este planteamiento de la RT reúne en la zona térmica 4, cuatro zonas climáticas, concentrando el $87 \%$ de la población de las 3 regiones de estudio (Figura 4).

La simplificación es observable en un comparativo de valores " $U$ " de transmitancia térmica y en la incompatibilidad de las zonificaciones. En general los valores se aproximan y las diferencias no son tan substanciales, solo el desfase de la RT en los muros frente a otros componentes de la envolvente lo que supone un desbalance en su mejoramiento (Figura 5).

La materialidad de las envolventes observada es consecuente con la generalización propuesta por la RT, una simplificación de la variedad de climas de tres regiones, localizadas entre las latitudes Sur $33^{\circ}$ (Región VII, Curicó) Sur $39^{\circ}$ (Región IX, Pucón) en medio de una amplia gama de altitudes entre el litoral, la cordillera de la costa, la depresión intermedia y la cordillera de los Andes (Figura 6). En ese aspecto, los materiales encontrados se apartan también de los actuales criterios de sustentabilidad y eficiencia energética, que hace énfasis en reconocer para cada proyecto las condiciones particulares del clima o microclima y geografía del lugar.

En el caso, por ejemplo, de los muros se limita a tres, y predomina una de ellas: la albañilería reforzada y/o confinada en primeros pisos $(77 \%)$, combinada en los segundos pisos con soluciones ligeras: estructuras en madera o metal, revestidas exteriormente en fibrocemento, madera o metal (Figura 7). Le siguen sistemas en madera
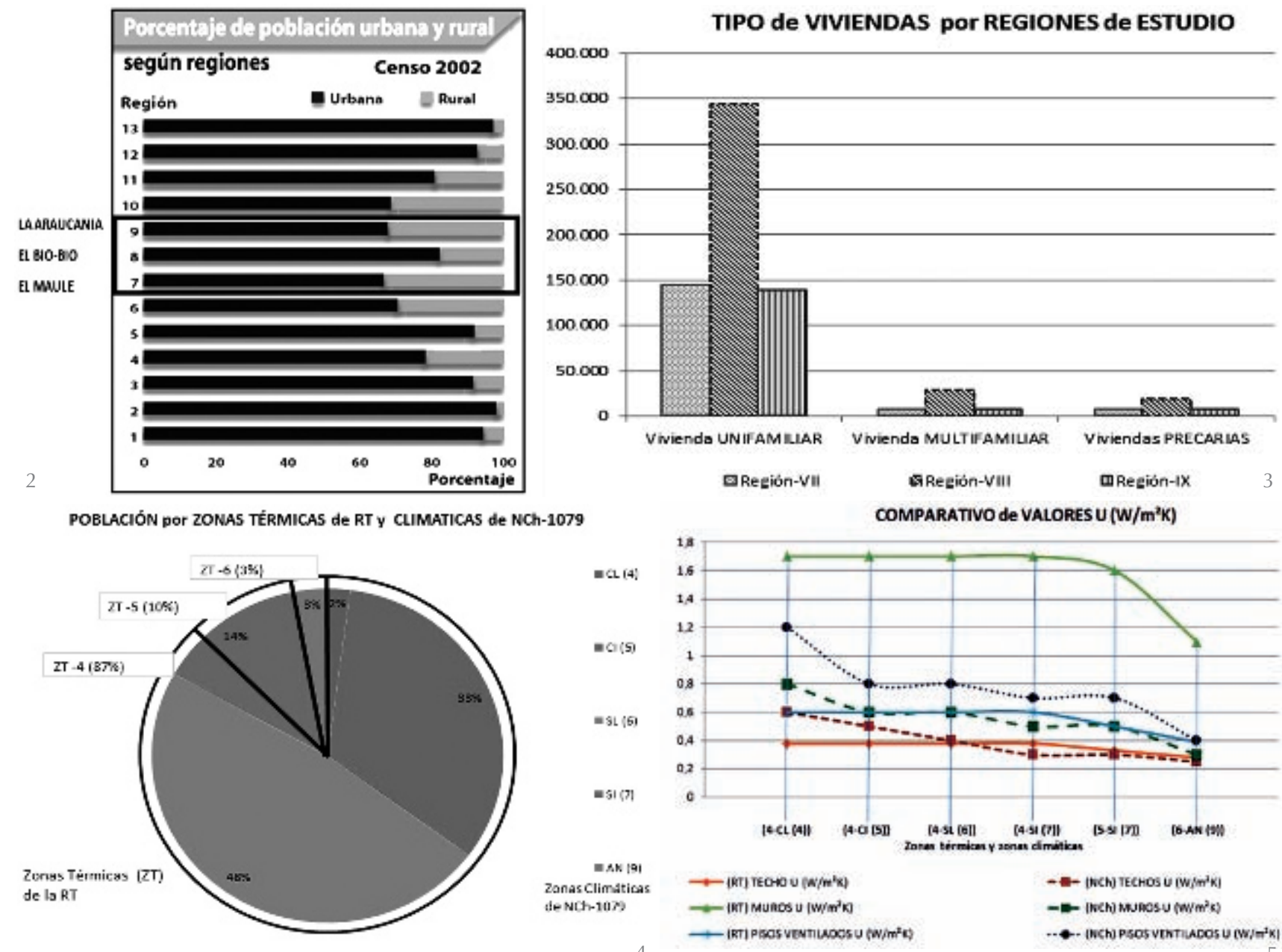


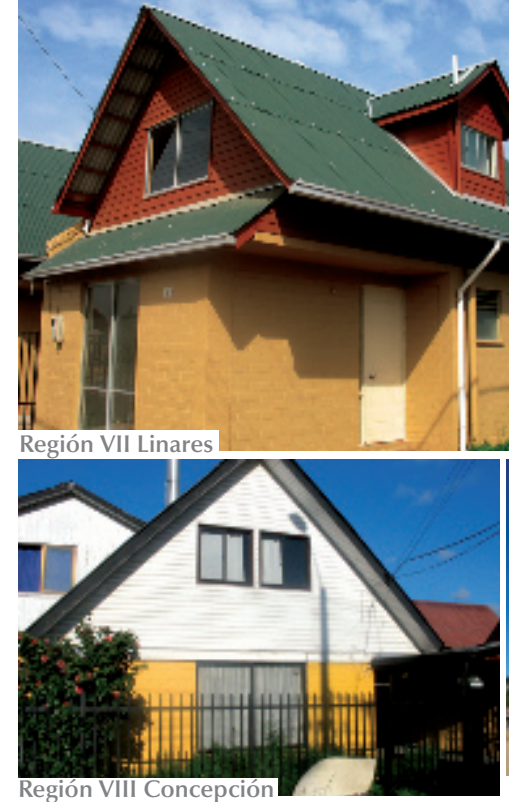

$(18 \%)$, en las zonas térmicas 5 y 6 , y finalmente algunas propuestas industrializadas (5\%), que siguen técnicamente la tendencia de las planteadas por los catálogos de vivienda certificada del Servicio de Vivienda y Urbanismo (SERVIU) para la reconstrucción. Los tipos de viviendas de los catálogos responden básicamente a la rapidez de ejecución pero no constituyen una muestra representativa ni una acción que perduró.

En la techumbre prevalece el uso de estructura en madera y cubiertas de planchas delgadas en metal (zinc) con una participación mínima en otros materiales, igual que en los catálogos SERVIU. Respecto a la ventanería tanto lo observado como los catálogos SERVIU señalan el uso extensivo de vidrio sencillo de $3 \mathrm{~mm}$ y marco en aluminio, continuado por plástico y madera, en última instancia. Los pisos, en su generalidad son de hormigón, sin ventilación, y sin aislación, aspecto no regulado en la RT.

Del comportamiento energético no se tienen comprobaciones en la zona que confirmen el estado de cumplimiento de la RT en las tres etapas después de la entrada en vigencia. No obstante, según algunas aproximaciones logradas por simulación (9), las demandas de calefacción, iluminación y agua caliente sanitaria, estarían en un rango promedio anual de $192 \mathrm{kWh} / \mathrm{m}^{2}$ año.

Otros estudios 5 indican que dicha demanda puede ser reducida para las regiones de estudio, en viviendas pareadas de dos pisos, alrededor de $110 \mathrm{KWh} / \mathrm{m}^{2}$ año.

Lo deseable para acercase a la realidad de lo consumos, pasa por la monitorización de viviendas. Internacionalmente el punto de partida para determinar consumos

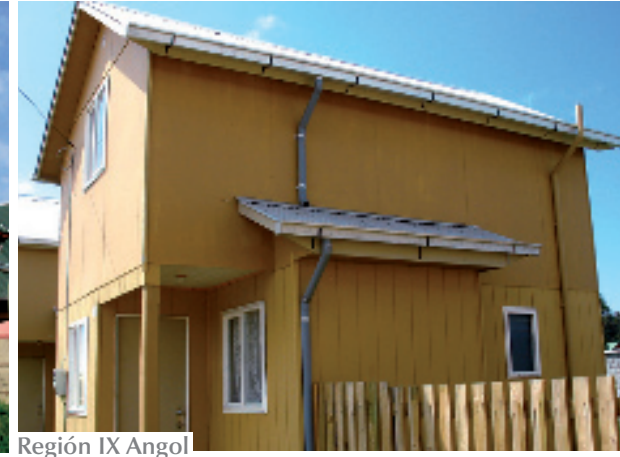

Comigencias entre la RT y la NCh en las regiones de estudio. Y la diferencia de los valores de transmitancia térmica " $U$ " de los muros de la RT $\left(1,7 \mathrm{~W} / \mathrm{m}^{2} \mathrm{k}\right)$ respecto a los otros componentes de la envolvente y a los de la NCh. 6: Comparativo de exigencias entre la RT y la $\mathrm{NCh}$ en las regiones de estudio. Y la diferencia de los valores de transmitancia térmica " $U$ " de los muros de la RT $\left(1,7 \mathrm{~W} / \mathrm{m}^{2} \mathrm{k}\right)$ respecto a los otros componentes de la envolvente y a los de la NCh.

6. Tipología y materialidad de envolventes en las 3 regiones de estudio (VII, VIII y IX).

7. Distribución de la materialidad de la envolvente de muros según las 22 ciudades observadas.

\section{MATERIALIDAD DE LA ENVOLVENTE: MUROS}

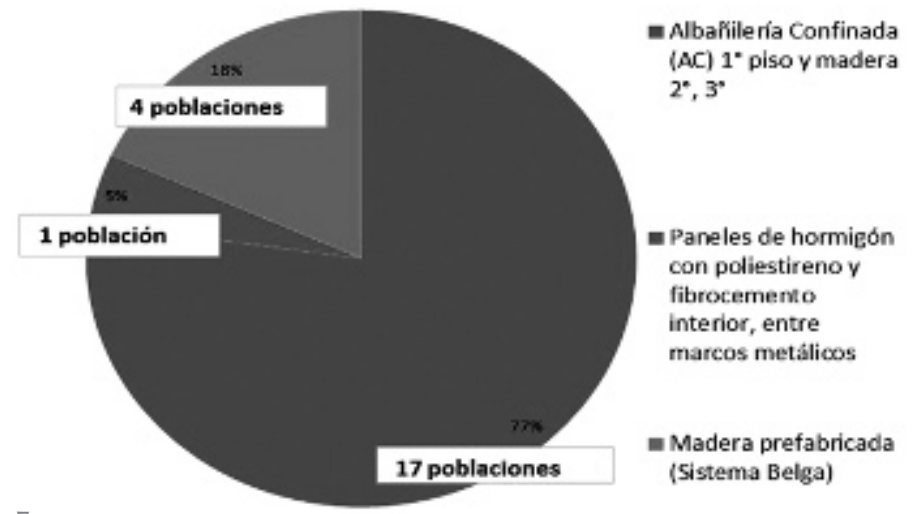

energéticos y precisar las estimaciones es la monitorización (10). Aplicados a viviendas sociales construidas, rehabilitadas o prototipos, han servido para analizar y establecer parámetros de consumos y hábitos. Así orientan en la adopción de estrategias de $\mathrm{EE}$, igualmente sirven a la afinación de programas de simulación, validación de condiciones reales de uso. Se apoyan en entrevistas y equipos de monitorización, alternativamente, para confrontar y precisar resultados. Discriminan o asocian consumos de calefacción e iluminación.

En resumen el parque de vivienda revisado indica que se trata predominantemente de viviendas pareadas de dos pisos y albañilería en primer piso y otras soluciones ligeras, en segundos pisos. Térmicamente su comportamiento energético establecido por estadísticas y simulaciones, está por comprobarse mediante monitorización. Se soporta en una normativa reducida frente a estándares internacionales con temperatura de base para cálculos de $15^{\circ} \mathrm{C}$, pero no de confort térmico interior en invierno ${ }^{6}$.
Guía de Diseño para Eficiencia Energética en la Vivienda Social (GDEEVS), pauta oficial, realiza simulaciones con TAS para las zonas climático-habitacionales estimando demandas de calefacción, a fin de precisar los ahorros. http://www.acee. cl/576/articles-61341_doc_pdf.pdf

${ }^{6}$ Las temperaturas de confort interior para invierno están entre $18-21^{\circ} \mathrm{C}$ en Europa. La estimación de $15{ }^{\circ} \mathrm{C}$ para grados día de calor, considerada en rango $12-16^{\circ} \mathrm{C}$ con riesgos de enfermedades respiratorias.

http://www.eci.ox.ac.uk/research/energy/ downloads/40house/chapter04.pdf 


\section{CONDICIONANTES AL COMPORTA- MIENTO DE LAS ENVOLVENTES}

El comportamiento de las envolventes mantiene estrecha relación con una serie de factores que inciden en el desempeño ambiental interior de las edificaciones y exige establecer verificaciones para su correcta aplicación desde la misma norma hasta las etapas de diseño, construcción y operación de las viviendas. Durante el observatorio de ejemplos en las regiones estudiadas y mediante entrevistas realizadas a profesionales, funcionarios y usuarios, se encuentra que los esfuerzos de regulaciones guías y manuales ${ }^{7}$, no logran subsanar todavía algunas debilidades que vale evidenciar para su mejoramiento.

En cuanto a la reglamentación obligatoria RT, su carácter menos exigente que la normativa recomendada NCh-1079-2008, ponen en duda su potencial energético. Además por el uso generalizado de la albañilería, precisamente en envolventes verticales, con niveles de prestación bajos respecto a otros materiales. A eso se suma la ausencia de controles efectivos en las Direcciones de Obras Municipales, limitadas a una declaración firmada con el único compromiso de responder a una eventual reclamación por parte del usuario, que puede empezar a hacer curso con la certificación integral de la vivienda y la acción de asociaciones de consumidores.

Otra de las alternativas para el cumplimiento de las exigencias térmicas, el listado oficial de soluciones constructivas (11), para el caso específico de muros de albañilería, se obliga a una aislación (exterior o interior), situación que no fue evidente durante el observatorio, al menos en muros exteriormente, pintados o a la vista en la mayoría de las situaciones. Y en los casos de estuco, no se detectaron medidas para su comprobación en obra, limitada a la declaración mencionada.

Una manera de motivar a los usuarios al control de la EE es dándoles información al momento de elegir vivienda, mediante la certificación, el etiquetado o declaración de consumos, una práctica reconocida en el mercado de equipos electrodomésticos, hoy referente voluntario en la oferta de vivienda de iniciativa privada. En planes habitacionales con patrocinio estatal todavía no se implementa, pero es un requisito creciente en edificios públicos.

7 En Programa País Eficiencia Energe tica, son múltiples recomendaciones, guías y consejos prácticos dirigidos a generar conciencia para la aplicación de medidas de aislamiento de la envolvente y uso de sistemas de calefacción y refrigeración e iluminación de bajo consumo.

Cfr. http://www.acee.cl/576/channel.html

En el caso de muros de albañilería, es pertinente también una revisión de compatibilidades entre las normas (12) en temas térmicos, de seguridad estructural y seguridad contra el fuego. En la primera situación por la permisividad de puentes térmicos en morteros de pega y en elementos que precisamente la hacen más segura ante sismo (pilares, cadenas y vigas) y paradójicamente, utilizada como cortafuego entre muros de madera, asume los mayores esfuerzos tensionales, debilitando o Ilevando al colapso los muros ligeros de segundos pisos, daño constante reportado durante el $27 \mathrm{~F}$ en las regiones de estudio.

Asimismo, para minimizar la ocurrencia de puentes térmicos, exigir en lugar de sugerir, la continuidad del comportamiento térmico en techumbres, muros, puertas y ventanas. La RT plantea exigencias sólo para ventanas y por limitación de porcentaje respecto a muro en vidriado simple o doble, lo cual no sucede en las puertas, afectando otros factores de habitabilidad y confort (Iluminación natural y/o artificial, calidad del aire).

Mejores prácticas se observan sobre techumbres con el uso de materiales estancos y aislados como acero galvanizado (zinc) preferidos sobre fibrocemento, más frágiles a golpes o sismo. La RT no es explícita en todas las soluciones, por lo menos de muro, sobre la adecuada colocación interior o exterior de los aislamientos pero sobre todo cómo medirlos y comprobarlos.

En la etapa de diseño el ahorro energético debe ser una exigencia. Las viviendas observadas en principio son precarias para las familias adjudicatarias, pues sus necesidades exceden los espacios ofrecidos, y no aseguran en su ampliación, las condiciones de habitabilidad y confort, eliminando una adecuada soleación y ventilación de las envolventes. En parques habitacionales recientemente entregados es evidente el desfase entre lo diseñado y lo necesitado.

En un ejercicio de costo/benéfico-social, los programas habitacionales en su diseño deben asegurar la integridad térmica de la envolvente en ampliaciones posteriores y señalar opciones de crecimientos preferiblemente al dar prioridad a los principios sobre aplicaciones en la normativa, es decir, proporcionar criterios a arquitectos de eficiencia energética por diseño, integrando los conceptos elementales de factor de forma o coeficiente de forma, tamaño, contacto y compacidad, básicos en temas energéticos para introducir los conceptos de EE, habitabilidad y confort (13), no mencionados en la RT.
Principios que pueden ayudar a entender que es más eficiente energéticamente una vivienda compacta que una irregular y que resulta más adecuado agrupar en hilera, que una distribución pareada o aislada; y 
en consecuencia que, por un factor de escala, las pérdidas se reducen entre más alto sea el edificio. Entonces, mejor proyectar en altura ( 5 pisos o más) que en 2 o en 1 piso, aunque mejor crujía simple y controlada para una adecuada orientación al sol y facilitar ventilaciones en verano. Son todos principios básicos, que sobre lo normado dan mayor claridad conceptual para actuar con criterio de sustentabilidad.

Por otra parte y a falta de una exigencia de ley, recomendar el empleo de ventanas con ensayos de permeabilidad, para evitar excesivas infiltraciones que generan pérdidas térmicas y preferir especificar ventanas batientes de hoja pequeña, para una ventilación controlada, sobre ventanas corredera, es una forma también de contribuir desde el diseño a la EE.

En la etapa de construcción, la EE encuentra barreras en el control de las soluciones constructivas. Estudios realizados indican que el desempeño térmico no logra los valores exigidos debido a los procesos de ejecución y a la baja calidad de ventanería, alcanzando pérdidas por infiltración que compiten con la transmitancia, y pueden representar en algunos casos el $60 \%$ de la demanda energética del edificio ${ }^{8}$.

Aislación, por ejemplo con láminas de fibra de vidrio de colocación manual, a falta de un efectivo control, presentan mayores deficiencias debido a las reconocidas dificultades para mantener la continuidad durante la instalación y su mantenimiento. Detalles constructivos adecuados que contemplen dichos riesgos y un monitoreo de la construcción, pueden prevenir discontinuidades y evitar humedad en muros o en suelos que aumentan su conductividad térmica. Un cambio puede darse con el uso de sistemas de aislación proyectada, sugeridos en el listado oficial, pero con la exigencia de pruebas de recepción o certificación.

En el caso de ventanería en aluminio, no incluida en la RT ni en el listado de soluciones constructivas, conviene el uso de materiales más estables y energéticamente más eficientes, junto a doble vidriado, ambos colaborantes en un mejoramiento energético de la envolvente.

La operación de la vivienda es clave en el desempeño de la envolvente. Efectivamente tiene las mayores implicaciones energéticas en atención a su participación en los tiempos que supone su vida útil, aproximadamente un $65 \%$, medidos en función de su impacto por emisiones de $\mathrm{CO}_{2}$. El tema, enfocado más a la rehabilitación de edificios (14) señala sin embargo por analogía de objetos de estudio para vivienda social orientaciones, en cuanto se trata en éstas de una intervención de "rehabilitación" térmica de envolventes.

En ese sentido, los esfuerzos de guías y manuales pueden ser infructuosos si no se suma la monitorización para los ajustes que se requieren. En el observatorio, se advierten sistemas de calefacción, previstos o funcionando, que utilizan la leña sin control de humedad, sumando a la ineficiencia energética el riesgo de contaminación por emisión de $\mathrm{CO}_{2}$. En lo que habrá necesidad de adelantar talleres de sensibilización ambiental con las comunidades, junto a incentivos para colaborar en un cambio de actitud que conduzca al uso de combustibles de bajo impacto.

Las envolventes son proclives también a condensación por el hacinamiento o por una precaria cultura de ventilación, aumentando ahora la producción de vapor con la práctica de incluir desde el diseño instalaciones de lavandería en los baños. Estudios (15) ponen de relieve la necesidad de incorporar el concepto de ventilación, compatibilizando la condición saludable del aire con el ahorro energético, a través de simulaciones encontrar las ubicaciones recomendables para las aberturas y, si existen restricciones de diseño, buscar (altura, ángulo y velocidad de aire, etc.). Igualmente profundizar en estudios de ventilación natural por diferencia de presión, inspirados en la arquitectura vernácula o de autorregulación de calefacción, señalan vías de solución.

Por otra parte, la percepción del confort varía y es menos exigente en los planes habitacionales cuyos pobladores vienen de condiciones muy precarias. Investigaciones en Chile empiezan a considerar la percepción de los usuarios como control de distorsiones y también para generar una cultura de habitabilidad y confort en usuarios de vivienda social.

\section{ANÁLISIS ENERGÉTICO DE ENVOLVENTE PREDOMINANTE}

Para la revisión del comportamiento energético de las envolventes predominantes, se suman a los criterios tenidos en cuenta en la observación, la materialidad de los muros, por cuanto es el único elemento de la envolvente que presenta una variedad relativa; techumbres, ventanería y pisos mantienen similares características, en las tres regiones. Así se seleccionan 8 muestras que reflejan en el conjunto de las 22 ciudades observadas la envolvente más representativa tanto en los planes de vivienda social patrocinados por el SERVIU como los ofertados por

\footnotetext{
${ }^{8}$ El proyecto "Establecimiento de clases de infiltración aceptables de edificios para Chile", demuestra mediante ensayos exploratorios que es un factor incidental en la EE. Cfr. Centro de Investigación en Tecnológica de la Construcción de la Universidad del Bio-Bio (CITEC-UBB). http://www.citecubb.cl/
} 
8. Participación porcentual de las soluciones seleccionadas. La materialidad predominante es albañilería confinada y/o reforzada en primer piso y tabiques ligeros de madera, en el segundo. el sector privado, comparados a las propuestas del banco de proyectos para la reconstrucción, desarrollados en las regiones más afectas por el 27F, Bio-Bio y Maule. La muestra arrojó una alta concentración de envolventes verticales en muros de albañilería $(88 \%)$ a la vista en primer piso y paneles ligeros (madera, fibrocemento y metal) sobre estructura en madera o metal, en el segundo (Figura 8).

\section{MATERIALIDAD DE MUROS EN LAS 8 CIUDADES} SELECCIONADAS

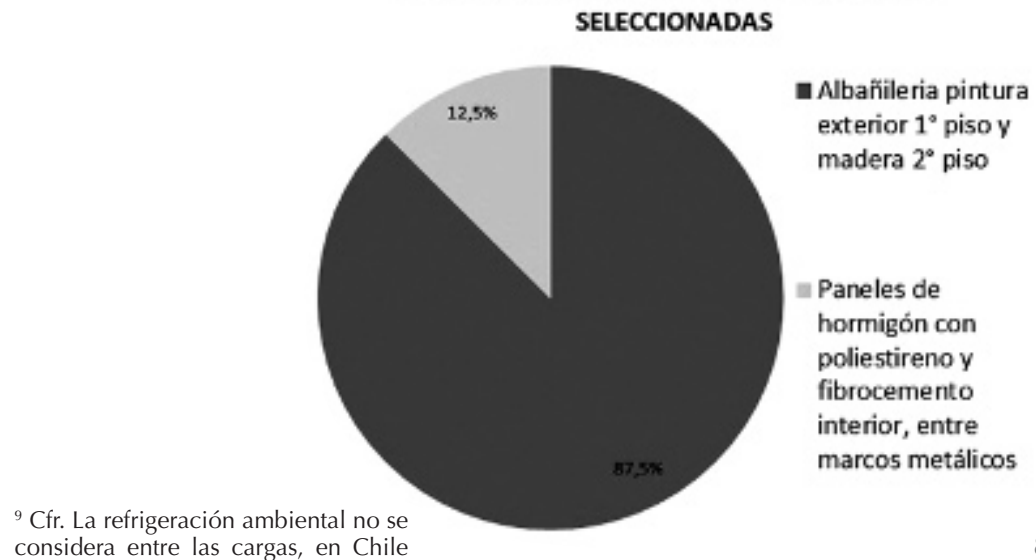
considera entre las cargas, en Chile prácticamente no se utiliza refrigeración (menos al $0.3 \%$ ). Los modelos de cálculo se pueden ver en [MINVU PPEE 2008-2]. http://www.acee. cl/576/articles-59188_doc_pdf.pd

${ }^{10}$ Siguen la escala de calificación energética propuesta por el CITECUBB. Ver también, Certificación Energética de Viviendas, IIT. Universidad de Concepción. (2009), p34. http:// barriosustentablecoronel.cl/pdf/sistema_de_certificacion_energetica_ de_viviendas.pd

${ }^{11}$ AutoDesk Ecotect. Analysis 2011.

${ }^{12} \mathrm{Cfr}$. El modelo se ajusta a los tipos supervisados por SERVIU para la reconstrucción, programas 200 viviendas (595-UF) y cumplen con los parámetros de la RT: www.minvu.cl
A partir de la participación porcentual de las soluciones constructivas seleccionadas, se elige para el análisis energético de la envolvente predominante (albañilería y madera) la zona metropolitana del Gran Concepción, en razón a su representatividad en cuanto a población con daños por el $27 \mathrm{~F}$ y cobertura de la zonificación térmico-climática: zonas térmica 4 y climática 6 (Tabla 2).

Se trata de evaluar su comportamiento energético, calificar su desempeño frente a la demanda de calefacción ${ }^{9}$ en la escala propuesta en Chile para diferenciar viviendas eficientes de no eficientes ${ }^{10}$, proponer mejoramientos y estimar los costos correspondientes para establecer estrategias de retorno de la inversión. A través de simulaciones simplificadas con el programa Ecotect ${ }^{11}$ que permiten dimensionar de manera general el comportamiento energético de la envolvente y orientar a su mejoramiento. El modelo de prueba es una vivienda social de $50 \mathrm{~m}^{2}$, compuesta por muros de albañilería en primer piso y tabiquería de madera en segundos ${ }^{12}$.

El análisis del desempeño energético de la envolvente se desarrolla comparando parámetros de aislación térmica de muros de fachada, de techumbres y ventanas, normados por la RT, otros no contemplados, de aislación térmica con pisos no ventilados (placas sobre terreno), aislación térmica de puente, aislación ponderada vertical y cambios de aire por infiltración, utilizando como valores limites los consignados por estudios para la certificación de desempeños para la zona ${ }^{13}$.

Son determinantes para la simulación, no intervenir los pisos, para sugerir acondicionamientos en viviendas ocupadas disminuyendo las incomodidades; y fijar los cambios de aire por infiltración en 1 cada hora a 50 pascales, conforme al software oficial CCTE 2.0, dispuesto para la certificación integral del MINVU. Valor que conviene comprobarse para determinar su incidencia en el desempeño.

Se realizan dos escenarios que se comparan con un caso base. El edificio de referencia es una vivienda que cumple con los mínimos valores de la RT vigente y con una demanda de $110 \mathrm{~kW}-\mathrm{h} / \mathrm{m}^{2}$ año ${ }^{14}$.

El primer escenario de mejoramiento tiene como objetivo alcanzar un ahorro del $20 \%$ de la demanda, es decir llegar a un tope de aproximadamente $80 \mathrm{~kW}-\mathrm{h} / \mathrm{m}^{2}$ año, incluye

Tabla 2. Cuadro síntesis de regiones, ciudades y población, y su relación con la zonificaciones térmica y climática.

\begin{tabular}{|c|c|c|c|c|c|}
\hline \multirow{2}{*}{\multicolumn{2}{|c|}{ REGIÓN }} & \multirow{2}{*}{ CIUDAD } & \multirow{2}{*}{ POBLACION } & \multirow{2}{*}{$\begin{array}{l}\text { ZONA TERMICA } \\
\text { LGUC }\end{array}$} & \multirow{2}{*}{$\begin{array}{c}\text { ZONA CLIMATICA-HABITACIONAL } \\
\text { NCH 1079-2008 }\end{array}$} \\
\hline & & & & & \\
\hline \multirow[t]{7}{*}{ VII-MAULE } & 1 & Constitucion & 46.081 & 4 & $\mathrm{CL}-4-$ \\
\hline & 2 & Talca & 238.817 & 4 & $\mathrm{Cl}-5-$ \\
\hline & 3 & Curico & 132.000 & 4 & $\mathrm{Cl}-5-$ \\
\hline & 4 & Cauquenes & 41.217 & 4 & $\mathrm{Cl}-5-$ \\
\hline & 5 & Linares & 100.604 & 4 & $\mathrm{Cl}-5-$ \\
\hline & 6 & Yerbas buenas & 16.134 & 4 & $\mathrm{Cl}-5-$ \\
\hline & 7 & Parral & 37.822 & 4 & $\mathrm{Cl}-5-$ \\
\hline \multirow[t]{9}{*}{ VIII-BIO-BIO } & 1 & Chillan & 161.953 & 4 & $\mathrm{Cl}-5-$ \\
\hline & 2 & Gran concepción & 1.013 .856 & 4 & SL -6- \\
\hline & & San pedro & -80.447 & 4 & $\mathrm{SL}-6-$ \\
\hline & & Penco & -46.016 & 4 & SL -6- \\
\hline & & Tome & -52.440 & 4 & $\mathrm{SL}-6-$ \\
\hline & & Dichato & -3.057 & 4 & $\mathrm{SL}-6-$ \\
\hline & 3 & Santa juana & 13.147 & 4 & $\mathrm{SL}-6-$ \\
\hline & 4 & Trehuaco & 5.161 & 4 & SL -6- \\
\hline & 5 & Los angeles & 166.556 & 4 & SI -7- \\
\hline \multirow[t]{6}{*}{ IX-ARAUCANIA } & 1 & Angol & 53.996 & 4 & $\mathrm{SI}-7-$ \\
\hline & 2 & Collipulli & 22.000 & 4 & SI -7- \\
\hline & 3 & Temuco & 303.813 & 5 & SI -7- \\
\hline & 4 & Pucón & 21.107 & 6 & AN -9- \\
\hline & 5 & Villarica & 45.531 & 6 & AN -9- \\
\hline & 6 & Caburgua & 1.000 & 6 & AN -9- \\
\hline
\end{tabular}


las aislaciones requeridas, realizadas al interior de la vivienda, ventanas con marcos en PVC, doble vidriado hermético: $3,6 \mathrm{~W} / \mathrm{m}^{2} \mathrm{~K}$ $\geq \mathrm{U}>2,4 \mathrm{~W} / \mathrm{m}^{2} \mathrm{~K}$; y se califica su desempeño con la respectiva estimación de costos de un mejoramiento de primer nivel (Figura 9).

Un segundo escenario fija un mayor ahorro energético, $50 \%$ respecto al base $( \pm 50 \mathrm{~kW}-\mathrm{h} /$ $\mathrm{m}^{2}$ año) $)^{15}$ corresponde a mejorar sustancialmente la envolvente de la vivienda, muros, techumbre, aplicando un sistema de aislación externa, sobrepuesto a la envolvente tipo "promuro" (EIFS: Exterior Insulation Finihs System), para disminuir las molestias de la intervención en los ocupantes. La calidad térmica de las ventanas es igual al escenario $\mathrm{N} .{ }^{\circ} 1$, y se estiman costos de mejoramiento de alto desempeño energético (Figura 10).

Los dos escenarios de mejoramientos aplicados a la envolvente térmica de la vivienda existente se comparan a los valores del caso base y se resumen en la representación polar de los parámetros medidos (Figura 11). Se observa en ambos escenarios los mejoramientos sustanciales de aislación de techumbres, puentes térmicos y ventanas. La diferencia, mejor en el escenario $\mathrm{N}^{\circ} 2$, radica en el porcentaje de área de puente térmico, debido a su eliminación por la continuidad de la aislación térmica sobre los bordes de placa de terreno y de entrepisos.

En contraste, en ambos escenarios se muestra la baja capacidad térmica de la envolvente en pisos por la decisión de no intervenirlos. No obstante, se realizan simulaciones para evaluar un mejoramiento en pisos. Así, aplicados al escenario $\mathrm{N} .^{\circ} 1$ se obtiene una reducción en la demanda de 80 a 60 kW-h/ $\mathrm{m}^{2}$ año, lo que sugiere empezar a considerar desde la norma la aislación de pisos sobre terreno o aplicarlo para monitorización en vivienda nueva y evaluar su impacto.

En opinión de entrevistados en relación a este ejercicio, coinciden en la necesidad de un monitoreo a la calidad de los materiales y de la ejecución con pruebas en terreno de

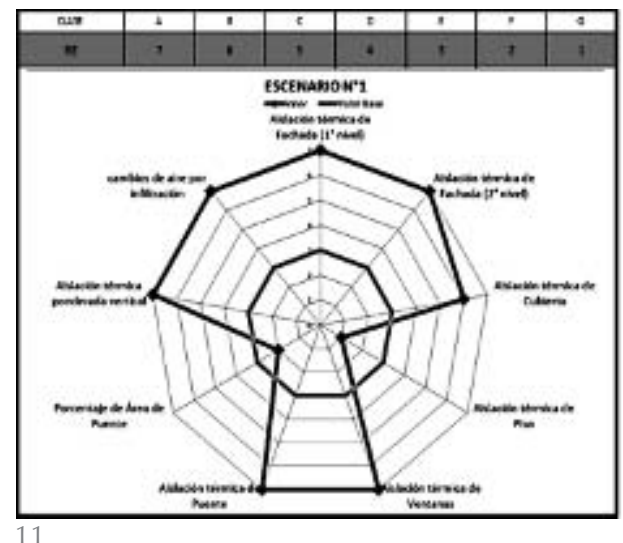

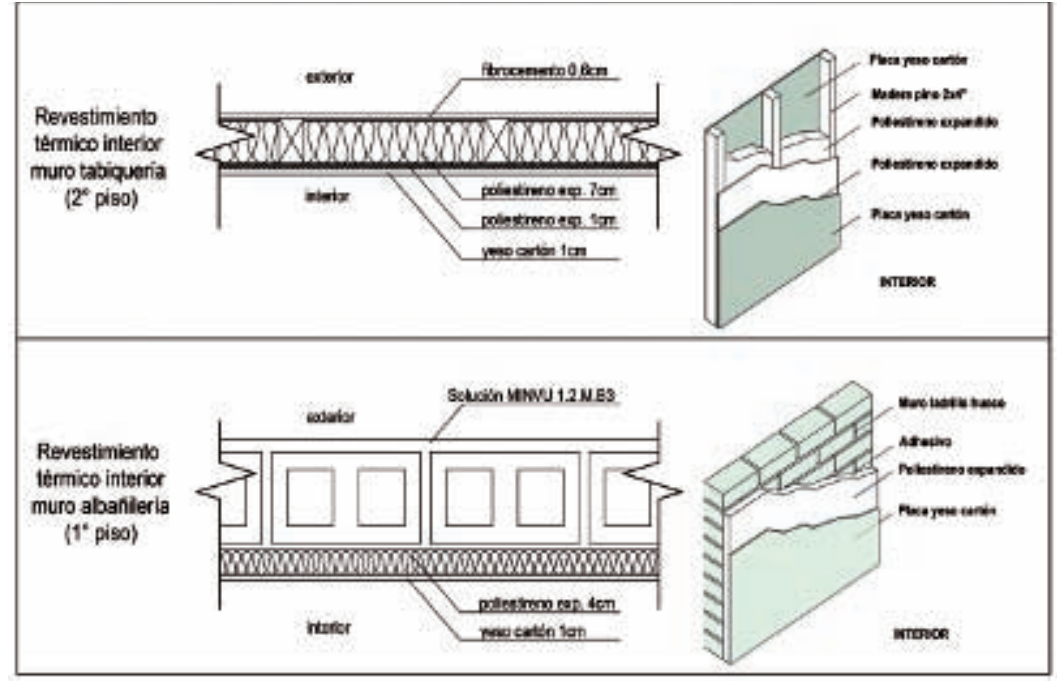

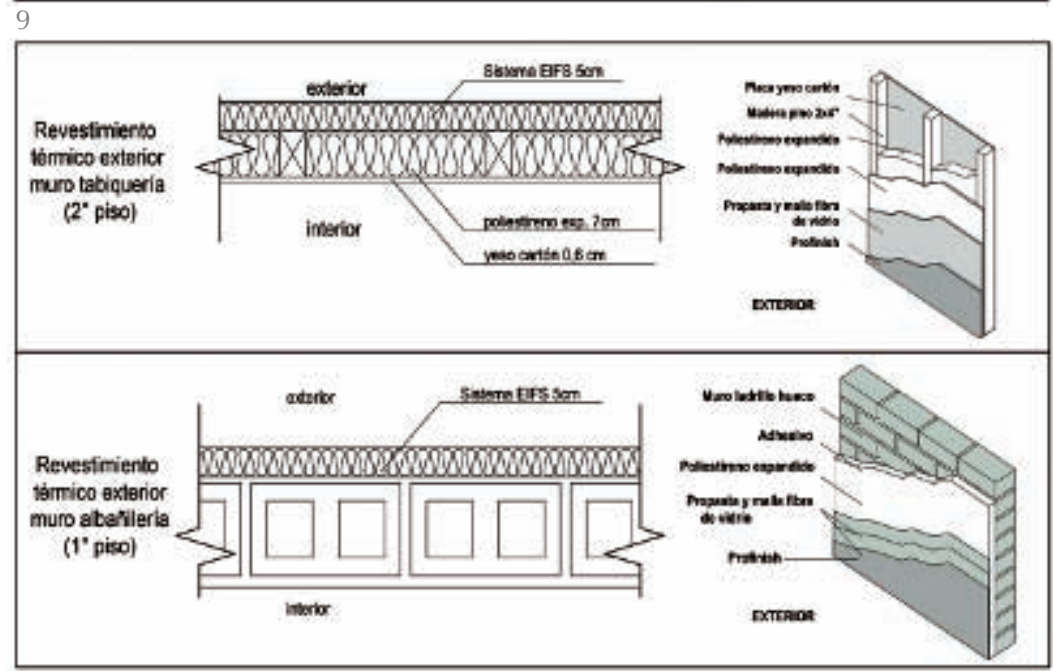

10

los desempeños, por cuanto es en esta etapa donde precisamente se estiman, independientemente a la limitada exigencia de la norma, los mayores desajustes entre simulación y realidad. Monitoreos en obras de la región demuestran que la construcción puede llegar a distorsionar y desmejorar los desempeños calculados teóricamente, en promedio de $40 \%$, en particular asociado a las infiltraciones y fugas de calor ${ }^{16}$.

Respecto a la capacidad para limitar la demanda de energía por calefacción, los resultados

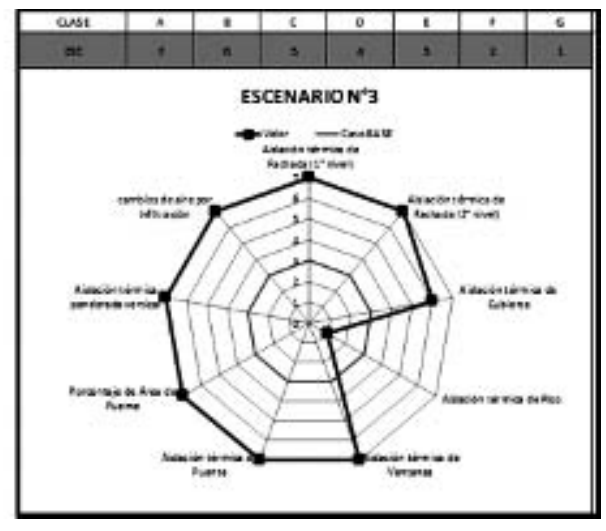

9. Escenarios 1: Aislación Interior. Detalles constructivos de las envolventes, en planta y vista.

10. Escenarios 2: Aislación Exterior. Detalles constructivos de las envolventes, en planta y vista.

11. Escenarios 1 y 2 del desempeño térmico de la envolvente de la vivienda, según representación polar de los 9 parámetros.

${ }^{13}$ Cfr. CITEC-UBB http://www.citecubb.cl/

${ }^{14}$ Estimativo promedio de valores para ciudades de la zona en viviendas de uno y dos pisos, de GDEEVS fuente citada (4).

${ }^{15}$ Los valores propuestos se ajustan al Programa de Inversión Pública para Fomentar el Reacondicionamiento Térmico del parque construido de viviendas (2007). p.6/26. El consumo óptimo, considera sólo medidas económicamente rentables en la actualidad y puede alcanzar valores del orden de $88\left[\mathrm{kWh} / \mathrm{m}^{2}\right.$ añol, lo cual implica un potencial de ahorro de $54 \%$. Considerando otras medidas, no económicamente rentables actualmente, pero alcanzables en un futuro cercano, se estima que se podría bajar a $40\left[\mathrm{kWh} / \mathrm{m}^{2}\right.$ año], con un potencial de ahorro del $80 \%$. http://www.acee. cl/576/articles-59188_doc_pdf.pdf 
12. Calificación de desempeño energético, escenarios 1 y 2 .

13. Resultados de consumos por combustible para 2 escenarios de mejoramiento térmico de la envolvente.
16 Mediciones realizadas por el CITEC-UBB en viviendas del Bío-Bío y de Araucanía mediante la técnica de la presurización (ASTM E779-87) proyecto Fondecyt No 920213.

17 Para llegar al valor fijado de cambios de aire por infiltración de $1 / \mathrm{h}$ a $50 \mathrm{~Pa}$, se hicieron tres simulaciones ECOTEC que muestran el aumento de la demanda energética respecto a $1 / \mathrm{h}$, en $41 \%$ para $2 / \mathrm{h}$ y $125 \%$ para $4 / \mathrm{h}$.

${ }^{18}$ Unidades de Fomento (UF), valor monetario variable por reajuste diario utilizado como referencia financiera en Chile. Cfr. http://www.sii.cl/ pagina/valores/uf/uf2012.htm

19 Los Subsidios para Acondicionamiento Térmico de la vivienda, están regulados por el Artículo 6 bis, DS $\mathrm{N}^{\circ}$ 255, V. y U. y fija el monto máximo a obtener, de acuerdo a la comuna en que se encuentre en un rango que va de 100 a 350 UF. Los postulantes deben aportar un ahorro mínimo de 3 UF Cfr. http://www.minvu.cl/opensite_det_20110502134513.aspx

${ }^{20}$ Cfr. Empresas de Servicios Energéticos: http://www.serviciosenergeticos.es/ para los dos escenarios son mostrados en un etiquetado para los $\mathrm{N}^{\circ} 1$ y $\mathrm{N}^{\circ} 2$ respectivamente con la calificación de los mejoramientos " $\mathrm{C}$ " (Buena) y " $\mathrm{A}$ " (Excelente), respecto al caso base, calificado con "E" (Figura 12). El ejercicio permite concluir que es posible alcanzar las reducciones estimadas de la demanda entre $20 \%$ y $50 \%$, con los materiales y tecnología disponibles en el sector de la construcción.

\begin{tabular}{|l|l|}
\hline $\begin{array}{l}\text { Calificación desempeño demanda } \\
\text { energética de Calefacción: ESCENARIO 1 }\end{array}$ & $\begin{array}{l}\text { Califlcación desempeño demanda } \\
\text { energètica de Calefacción: ESCENARIO } 2\end{array}$ \\
\hline
\end{tabular}
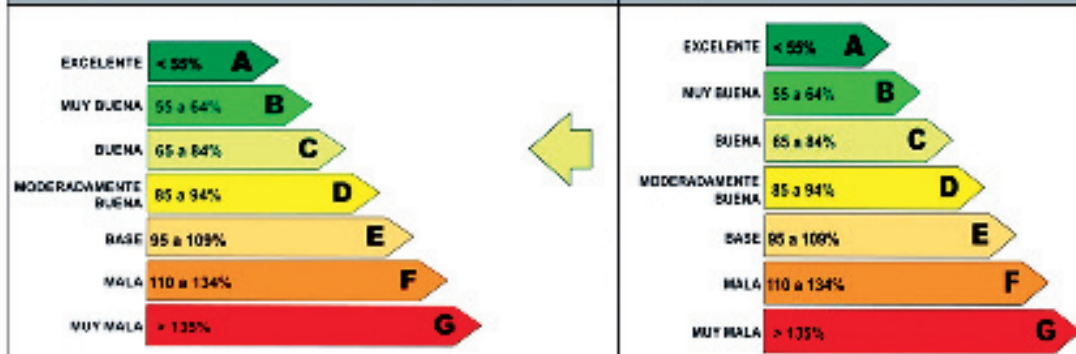

Los resultados además tienen una relación directa con el poder aislante de la envolvente, aunque se advierte sobre la necesidad de atender el nivel de infiltraciones de aire. En efecto, se detecta en las aproximaciones para alcanzar los ahorros fijados, la influencia de los cambios de aire por infiltración, variable paradójicamente considerada como constante $(1 / \mathrm{h})$ en el software oficial de certificación SERVIU, lo cual puede llevar a distorsiones en el cálculo de los ahorros ${ }^{17}$.

Calificados los desempeños se procede a calcular los costos de mejoramiento y a estimar los ahorros que se pueden alcanzar. Los mejoramientos calculados a precios de Unida- des de Fomento $(U F)^{18}$, se encuentran dentro de los subsidios actuales para acondicionamiento térmico, fijados en UF ${ }^{19}$. En el escenario $\mathrm{N}^{\circ} 1$ el costo total de mejoramiento está en 85 UF y para el escenario $\mathrm{N}^{\circ} 2$ en 120 UF.

El cálculo de los consumos para calefacción se hacen en UF con combustibles tradicionalmente empleados en las regiones de estudio.

\section{CONSUMOS ENERGÉTICOS POR CALEFACCOÓN}

\begin{tabular}{|l|r|r|r|}
\hline ESCENARIo & $\begin{array}{c}\text { CONSUMO ANUAL } \\
\left(\mathrm{kW}-\mathrm{h} / \mathrm{m}^{2}\right)\end{array}$ & $\begin{array}{c}\text { GAS LCUADO } \\
\text { (Costo UF/año) }\end{array}$ & $\begin{array}{c}\text { LEÑA (Costo } \\
\text { UF/año) }\end{array}$ \\
\hline Linea base & 110,0 & 24,7 & 8,3 \\
\hline Escenario 1 & 80,0 & 15,2 & 6,0 \\
\hline Escenario 2 & 50,0 & 9,7 & 3,8 \\
\hline
\end{tabular}

Ur:Unida des de romento, valor monetafio vafiable por reajuste dia fio utilizado como referencia financiera en chile.

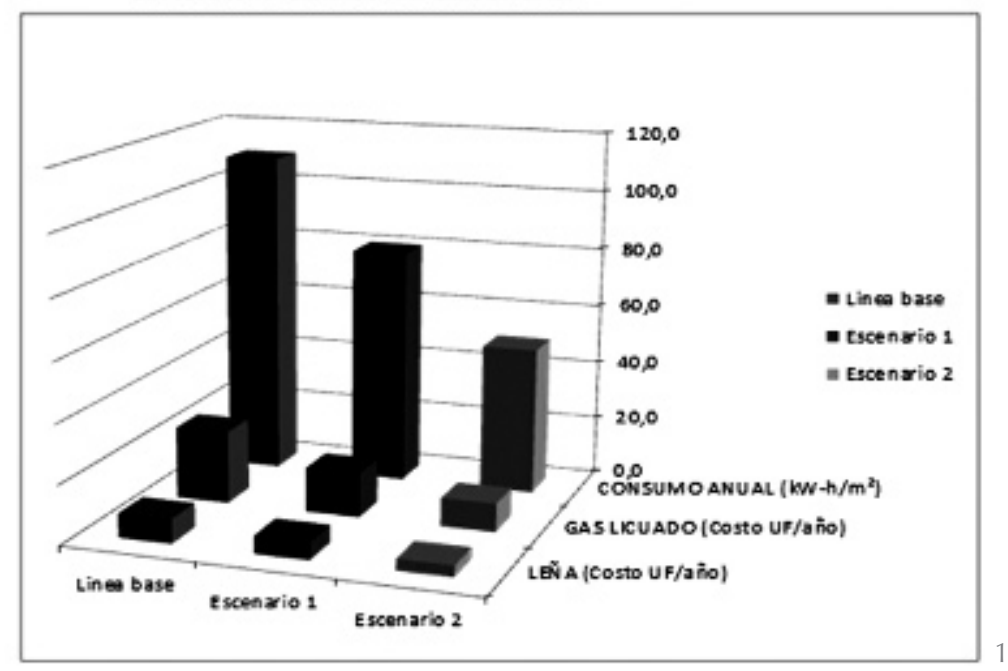


En el cuadro síntesis (Tabla 3) se observan resultados del mejoramiento térmico de la envolvente en los dos escenarios contemplados y el retorno de la inversión en 15 años con ahorros por consumo/mes de calefacción con gas licuado durante un año. En los dos escenarios evaluados con calificación (Buena) o A (Excelente), es posible amortizar los costos con los ahorros de consumo por mes de combustible, para revisar posteriormente en una monitorización.

De las valoraciones financieras se puede afirmar que están resueltos dentro de los rangos de los subsidios, y son factibles con la tecnología disponible. Para garantizar que los acondicionamientos térmicos de viviendas sean una herramienta efectiva para la EE deberían afinarse mecanismos adecuados de regulación y control, con asesorías en las etapas de diseño, monitoreo en la construcción, certificación en la recepción de la obra y una periódica comprobación de desempeños e idoneidad técnica, durante la vida útil de la vivienda.

Finalmente, la relación entre demandas de calefacción y consumos energéticos en la zona de estudio, consecuente con el parque de vivienda (24\%), la población que reúnen las 3 regiones de estudio ( $24 \%$ del total del país), su simplificación climática -de 5 a 3-, y la envolvente predominante (albañilería: 77-87\%), son razones que justifican un análisis detallado y comprobación experimental, en etapa de construcción y ocupación, que permita evaluar la rentabilidad de la inversión y logros económicos y ambientales.

\section{CONCLUSIONES}

La reconstrucción por el terremoto del $27 \mathrm{~F}$, es una oportunidad para poner en marcha acciones que pueden reducir el relevante consumo energético de las viviendas, que en Chile tienen una participación del $22 \%$, correspondiendo principalmente a calefacción debido a las condiciones climáticas en las zonas mas afectadas, objeto de este estudio.

Las características de la envolventes son especialmente relevantes en esta zona debido al parque habitacional, eminentemente urbana, viviendas unifamiliares pareadas
AHORROS AÑO/MES POR CONSUMOS DE COMBUSTIBLF

\begin{tabular}{|l|r|r|r|}
\hline \multicolumn{1}{|c|}{ ESCENARIO } & $\begin{array}{c}\text { GAS LICUADO } \\
\text { (Costo UF/ahio) }\end{array}$ & Ahorro (UF/anio) & Nhorro (UF/mes) \\
\hline Line a base & 24,7 & $\mathbf{0 , 0}$ & $\mathbf{0 , 0}$ \\
\hline Escenario 1 & 15,2 & $\mathbf{9 , 5}$ & $\mathbf{0 , 7 9}$ \\
\hline Escenario 2 & 9,7 & 15,0 & $\mathbf{1 . 2 5}$ \\
\hline
\end{tabular}

Ur: unidades de romento, valor monetano vanable por feajuste dia no uviliza do como referencia financiers en ovile.

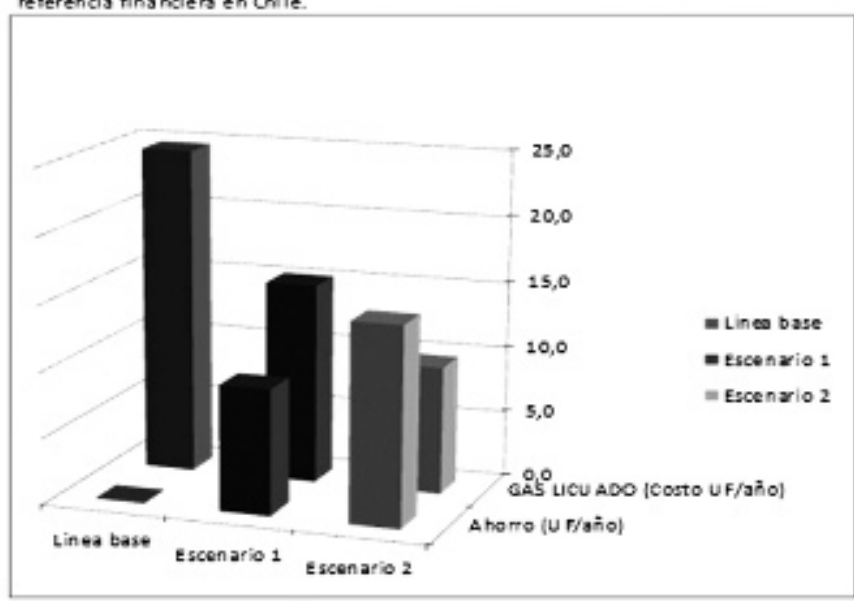

en uno y dos pisos. La materialidad predominante $(77 \%)$ es albañilería confinada y tabiquería ligera, con techumbre de madera, aplica una regulación normativa que simplifica la variedad de climas. Reclama su revisión para una mayor EE, en relación a estudios locales y estándares internacionales (sub-zonificación climática-habitacional) que permitirían particularizar y disminuir los consumos.

La normativa térmica de las envolventes habitacionales es reducida frente a regulaciones en climas similares, especialmente en muros, vanos y techos. Es limitada a transmitancia, permisiva en puentes térmicos, y no atiende pérdidas térmicas ocasionadas por infiltración de aire en la envolvente.

Factores concomitantes, norma, diseño, construcción y ocupación afectan la hermeticidad y restan efectividad a las acciones de EE. Armonizarlas con medidas de análisis y control de desempeños, pueden contribuir a un mejoramiento efectivo. La declaración de diseñadores acompañada de asesorías técnicas, monitorización y encuestas postocupación o etiquetado del gasto energético, garantizarían metas consecuentes.

Evaluación de dos escenarios de mejoramiento de envolvente, en relación a un caso
14. Resultado de ahorros por consumos de combustible para dos escenarios de mejoramiento térmico de la envolvente.

Tabla 3. Cuadro síntesis resultados de mejoramiento y retorno de la inversión en uf (Unidades de Fomento)

\begin{tabular}{|c|c|l|c|c|c|c|c|}
\hline Escenario & $\begin{array}{c}\text { Demanda } \\
\text { energética } \\
\mathbf{k W}-\mathbf{h} / \mathbf{m}^{2} \text { año }\end{array}$ & $\begin{array}{c}\text { Calificación } \\
\text { desempeño }\end{array}$ & $\begin{array}{c}\text { Costo } \\
\text { mejoramiento } \\
\text { Envolvente } \\
\text { CME) Vivienda } \\
\text { Social (VS) }\end{array}$ & $\begin{array}{c}\text { Consumo gas } \\
\text { licuado en } \\
\text { UF/mes }\end{array}$ & $\begin{array}{c}\text { Ahorro } \\
\text { consumo gas } \\
\text { licuado en } \\
\text { UF/mes }\end{array}$ & $\begin{array}{c}\text { Cuota crédito } \\
\text { mejoramiento } \\
\text { UF/mes }(5,4 \% \\
\text { anual a } 15 \text { años) }\end{array}$ & $\begin{array}{c}\text { Balance } \\
\text { económico: } \\
\text { Ahorro - Cuota } \\
\text { crédito }\end{array}$ \\
\hline 0 & 110 & E (Base) & 0 & 2,06 & 0,00 & 0,00 & 0,00 \\
\hline 1 & 80 & C (Buena) & \pm 85 UF & 1,26 & 0,79 & 0,68 & 0,11 \\
\hline 2 & 50 & A (Excelente) & \pm 120 UF & 0,81 & 1,25 & 0,97 & 0,28 \\
\hline
\end{tabular}

UF: Unidades de Fomento, valor monetario variable por reajuste diario utilizado como referencia financiera en Chile. 
base, permiten identificar estrategias efectivas de disminución de consumo energético, alcanzables en programas estatales de construcción y rehabilitación de viviendas.

El análisis energético debido al mejoramiento planteado, disminuye la transmitancia de la envolvente y presenta una reducción significativa en consumos energéticos (hasta un 50\%: alcanzando 50KW-hm² año). Las simulaciones efectuadas demuestran la necesidad de complementar la RT con aislación térmica de pisos no ventilados, de puente térmico, ponderada vertical y precisar los cambios de aire por infiltración.

Las estrategias de mejoramiento sugeridas de envolventes de viviendas existentes (EIFS) implican un menor impacto en la ejecución. Se señalan ahorros por consumos de combustible con gas licuado, desestimulando el empleo de la leña, que en el contexto de la zona analizada está asociada a la imagen de calor. Requiere no obstante de un estudio sociocultural, talleres de educa- ción ambiental junto a incentivos económicos para un cambio de actitud que conduzca al uso de combustibles de bajo impacto. El análisis económico y financiero, sugiere tres alternativas de retorno de la inversión (subsidios, recursos propios o empresas de servicios energéticos). Pronóstico de desempeño a contrastar con monitorizaciones para evaluar la rentabilidad efectiva de los mejoramientos propuestos.

\section{AGRADECIMIENTOS:}

Los autores agradecen a la Agencia Chilena de Eficiencia Energética y a la Comisión Nacional de Investigación Científica y Tecnológica por la financiación de este proyecto de investigación; al Msc. Ariel Bobadilla, director del CITEC-Bio-Bio y al Msc. Reinaldo Sánchez por su atención a los aspectos energéticos; a las arquitectas Derlin Ariza y Muriel Díaz por su colaboración en los temas técnicos, y a los entrevistados, copartícipes en diseño, construcción y uso de viviendas sociales por sus opiniones.

\section{BIBLIOGRAFÍA}

(1) Ministerio de Vivienda y Urbanismo (MINVU). Estado de situación del sector, Chile 2010. http://www. gobiernodechile.cl/cuenta-publica-2010/ministerio-de-vivienda-y-urbanismo/cuenta-sectorial/

(2) Comisión Nacional de Energía de Chile (CNE). Consumo porcentual por sectores de energía secundaria en Chile. Promedio año 1998 al 2007, en Eficiencia energética en vivienda: un desafío posible. http://vinculosconlasociedad.uc.cl/documentos/12615031554666.pdf

(3) Ministerio de Vivienda y Urbanismo (MINVU). Manual de Aplicación de la Reglamentación Térmica, Chile 2009. http://www.minvu.cl/opensite_20070417155724.aspx

(4) Bustamante, W.: Guía de diseño para la eficiencia energética en la vivienda social. Chile 2009. http://www.acee.cl/576/articles-61341_doc_pdf.pdf

(5) Trebilcock, M.: "Percepción de barreras a la incorporación de criterios de eficiencia energética en las edificaciones". Revista de la construcción, Vol. 10 n 1 (2011), pp 4-14.

(6) "Corporación de Desarrollo Tecnológico de la Cámara Chilena de la Construcción Y PPEE". Manual técnico Reacondicionamiento térmico de viviendas en uso. Chile, 2010. http://www.barriosustentablecoronel.cl/PDF/Reacondicionamiento_termico_viviendas.pdf

(7) Instituto Nacional de Estadísticas (INE) Chile. Censo 2002. http://www.ine.cl/canales/chile_estadistico/demografia_y_vitales/demografia/demografia.php

(8) Instituto Nacional de Estadísticas (INE) Chile. Síntesis Censal 2002. http://www.ine.cl/cd2002/ sintesiscensal.pdf

(9) Instituto de Investigaciones Tecnológicas y Asistencia Técnica, (IIT). Universidad de Concepción. (2009) Sistema de Certificación Energética de Viviendas: http://barriosustentablecoronel.cl/PDF/SISTEMA_DE_CERTIFICACION_ENERGETICA_DE_VIVIENDAS.pdf

(10) León; A.L.; et ál.: "Monitorización de variables medioambientales y energéticas en la construcción de viviendas protegidas: Edificio Cros-Pirotecnia en Sevilla". Informes de la Construcción, Vol. 62 no 519 (2010), pp. 67-82. doi: 10.3989/ic 09.045.

(11) Ministerio de Vivienda y Urbanismo (MINVU): "Estado de situación del sector, Chile, 20112, Listado oficial de soluciones constructivas para acondicionamiento térmico. http://www.google.cl/ search?q=Listado+oficial+de+soluciones+constructivas+para+acondicionamiento+t $\% \mathrm{C} 3 \% \mathrm{~A} 9 \mathrm{rmi}$ co\&ie=utf-8\&oe=utf-8\&aq=t\&rls=org. mozilla:es-CL:official\&client=firefox-a

(12) Ministerio de Vivienda y Urbanismo (MINVU) Chile, 1992. Ley Ordenanza General de Urbanismo y Construcción (LOGUC), De las condiciones de habitabilidad Art.4.1.1. en Título 4. de La Arquitectura, capítulo 1. http://www.minvu.cl/opensite_20070223152342.aspx

(13) Manfred, H.: Energy Manual: Sustaintable Architecture, p. 64, Edition Detail Munich. Berlin, 2008.

(14) Waldel, G.; et ál: "Rehabilitación de edificios bajo objetivo de reducción de impacto ambiental: un caso piloto de vivienda plurifamiliar en el área de Playa de Palma, Mallorca". Informes de la Construcción, Vol. 63 no 519 Extra (2011), pp. 89-102. doi: 10.3989/ ic 11.067.

(15) Meiss, A.; et ál: "Influencia de la ubicación de las aberturas en la eficiencia de la ventilación en viviendas". Informes de la Construcción, Vol. 63 nº 522 (2011), pp. 53-60. doi: 10.3989/ ic 10.001. 


\title{
Fachadas ventiladas activas para reducir la demanda de calefacción en los edificios de oficinas. El caso de España
}

\author{
Ventilated active façades to reduce heating demand \\ in office buildings. The case of Spain
}

O. Irulegi(*), A. Serra(*), R. Hernández ${ }^{(*)}$, A. Ruiz-Pardo(**), L. Torres ${ }^{(*)}$

RESUMEN

En este artículo se analiza la eficiencia energética de una Fachada Ventilada Activa -FVA- aplicada a edificios de oficinas en España para reducir la demanda de calefacción.

El sistema de fachada consiste en una hoja exterior de $2 \mathrm{~mm}$ de acero galvanizado y una cavidad de $3 \mathrm{~cm}$ donde el aire de ventilación es precalentado en invierno y extraído en verano.

Tras definir 8 tipologías típicas, se han obtenido 192 casos de estudio en los que se consideran diferentes parámetros: la superficie acristalada, la orientación y la zona climática.

El cálculo de la demanda energética de los casos de estudio ha sido llevado a cabo mediante el programa LIDER, el método general del Código Técnico de la Edificación - CTE. Los resultados obtenidos en términos de reducción de la demanda de calefacción, se muestran comparados con los mínimos requerimientos exigidos en el CTE.

$113-121$

Palabras clave: Eficiencia energética; estrategias de calefacción; fachada ventilada activa; oficinas.

\section{SUMMARY}

This paper analyses the energy efficiency of a Ventilated Active Façade -VAFapplied to office buildings in Spain to reduce heating demand.

This façade system consists of an outer layer element of $2 \mathrm{~mm}$ galvanized steel panels and a $3 \mathrm{~cm}$ air cavity where the ventilation air is preheated in winter and exhausted in summer.

After defining 8 typical office typologies in Spain, 192 study cases are obtained where different parameters like the percentage of glass in façade, the orientation and the climatic zone of the buildings are considered.

The energy demand of all these study cases is obtained using the official simulation tool of the Spanish Technical Building Regulation - CTE called LIDER. The results, in terms of reduction of heating demand, are presented in comparison with the minimum energetic requirements of CTE.

Keywords: Energy efficiency; heating strategies; ventilated active façade; office buildings.

\footnotetext{
(*) ETSA, Universidad del País Vasco. San Sebastián (España).

(**) Escuela Superior de Ingenieros, Universidad de Sevilla (España).

Persona de contacto/Corresponding author: o.irulegi@ehu.es (O. Irulegi)
} 